\title{
Evaluation of Three Different Extenders for Use in Emergency Salvaging of Epididiymal Spermatozoa from a Cantabric Brown Bear
}

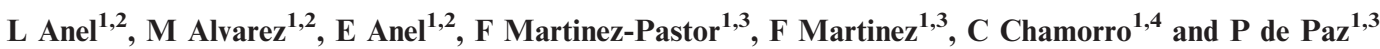 \\ ${ }^{1}$ ITRA-ULE, INDEGSAL; ${ }^{2}$ Animal Reproduction and Obstetrics; ${ }^{3}$ Cell Biology; ${ }^{4}$ Veterinary Anatomy, University of León, León, Spain
}

\begin{abstract}
Contents
The Cantabrian brown bear (Ursus arctos) constitutes an endangered subpopulation of the European brown bear in the north of Spain. We have carried out a post-mortem recovery of epididymal spermatozoa from a Cantabrian brown bear (7 years old, $170 \mathrm{~kg} ; 30 \mathrm{~min}$ post-mortem), cryopreserving those recovered from the cauda epididymis $\left(929 \times 10^{6}\right.$ spermatozoa, 54\% motile, $82 \%$ cytoplasmic droplets). For freezing, three extenders based on Test-Tris-Fructose $+4 \%$ glycerol were used: (1) $325 \mathrm{mOsm} / \mathrm{kg}$ and $10 \%$ egg yolk; (2) $430 \mathrm{mOsm} / \mathrm{kg}$ and $15 \%$ egg yolk; (3) $300 \mathrm{mOsm} / \mathrm{kg}$, EquexEDTA and $20 \%$ egg yolk. After thawing, we obtained higher motility for extender $3(31 \%)$, but extender two yielded the highest viability $(66.9 \%)$ and mitochondrial activity $(67.1 \%)$. Caffeine stimulation showed that extender two rendered the highest recovery values of post-thawing motility with respect to the fresh sample. In conclusion, epididymal spermatozoa of brown bear can be frozen applying an extender with osmolality similar to epididymal environment.
\end{abstract}

\section{Introduction}

Epididymal spermatozoa are an important source of germplasm for biological resource banks, and the collection of such samples is usually the only possibility to preserve gametes from animals of high value or from endangered species (Leibo and Songsasen 2002; Fickel et al. 2007). Epididymal spermatozoa obtained from the cauda epididymis have been used in many assisted reproduction techniques. There have been reports on embryo production and pregnancies utilizing spermatozoa from the epididymis (Tsutsui et al. 2003; Hori et al. 2004).

However, in the case of wild animals, the death of valuable individuals happens often unexpectedly in the wild. In this situation, sperm collection must be carried out quickly and often must be delegated on people extraneous to the germplasm bank. In this case, it is necessary that samples are transported from the field to laboratories as soon as possible to increase the chances for a successful future use of the sample (Anel et al. 2002a, 2008; Soler et al. 2003; Martinez-Pastor et al. 2004; Sato and Ishikawa 2004). This situation requires an adequate knowledge of the epididymal samples and maturation status (De Pauw et al. 2003) and, therefore, effective cryopreservation methods.

Bears represent one case with little available information about epididymal spermatozoa cryopreservation (Anel et al. 2008). At present, six species, among the eight known, are endangered. In the case of brown bear, many subpopulations with unique genetic traits are threatened (Clevenger et al. 1997; Chapron et al. 2003). Up to date, there are many studies on the reproductive biology of the American black bear (Ursus americanus), Japanese black bear (Ursus thibetanus japonicus) and several subspecies of brown bear (Ursus arctos) (Komatsu et al. 1997, Tsubota et al. 1997; Holt and Watson 1 2001; Sato et al. 2001; Ishikawa et al. 2002a; Boone et al. 2004). The studies about obtaining sperm by electroejaculation or spermatozoa cryopreservation are scarce (Ishikawa et al. 1998, 2002b; Kojima et al. 2001; Anel et al. 2003; Garcia-Macias et al. 2004), and there are no studies on epididymal sperm.

Brown bear is an endangered species in Spain, and the last individuals (approximately 80 animals) survive in two separated subpopulations in the Cantabric Mountains. Their situation is very delicate by a high risk of inbreeding because of the small size of both subpopulations (Taberlet and Bouvet 1994; Laikre et al. 1996). Thus, there is a great concern on assuring the viability and genetic health of these subpopulations accordingly to the Spain National Species Recovery Plan (law 4/1989). Considering this situation, the banking of biomaterials would be an adequate measure to effectively manage the available genetic resources.

In this work, we have described an emergency procedure carried out for salvaging and cryopreserving the epididymal sperm of an accidentally deceased brown bear from one of the referred populations. Some partial data of spermatozoa (recovery rate, morphological parameters and motility) were presented in a previous communication (Anel et al. 1999). Because of the suddenness of the situation, extenders could not be prepared in advance, and they were selected among the current existences of our laboratory, keeping in mind the characteristics of the sample. Our aim is to provide some data regarding characteristics and cryopreservation of epididymal samples from brown bears, which may help other researchers to solve a similar situation. Currently, we are carrying out different experiments to obtain, analyse and cryopreserve brown bear sperm obtained by means of electroejaculation.

\section{Materials and Methods}

All chemicals were acquired from Sigma (The Nether- $\mathbf{2}$ lands). Media were not bought as such, but prepared in our laboratory as described, except for PBS medium.

\section{Sperm recovery}

A Cantabrian brown bear (7 year old and $170 \mathrm{~kg}$ of weight) suffered an accident on 3rd May 1998, in the Cantabric Mountains range (Somiedo Natural Park; Asturias, Spain). It died during the transport to the

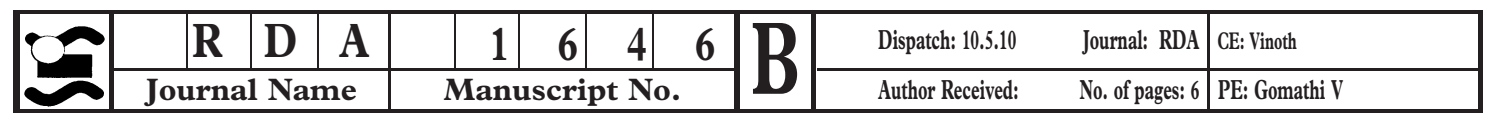


Clinic Veterinary Hospital of the University of León. At arrival (approximately $30 \mathrm{~min}$ post-mortem), the testicles were removed from the carcass, and the epididymides were dissected and divided in caput, corpus and cauda. The weight of each isolated piece (testicles and the caput, corpus and cauda epididymis) was recorded. Animal manipulations were performed in accordance with Spanish Animal Protection Regulation RD223/ 1998, which conforms to European Union Regulation 86/609.

Samples were obtained separately from testis and the caput, corpus and cauda epididymis by means of cuts, taking care not to contaminate the sample with of the tissue blood. Because the spermatozoa from testis, caput or corpus were not motile, those samples were used only for abnormal forms and cytoplasmic droplets assessment (Anel et al. 1999). The weight of the fluid from each cauda epididymis was weighed separately. Afterwards, the samples from the two cauda epididymis were mixed and treated as one sample.

\section{Assessment of fresh sample}

The sperm concentration of the sample (spermato$\mathrm{zoa} / \mathrm{ml}$ ) was calculated using a Burker counting chamber, after diluting the sample in a glutaraldehyde solution $(5 \mu \mathrm{l}$ of sample in $500 \mu \mathrm{l}$ of $2 \%$ glutaraldehyde in an aqueous solution made of $29 \mathrm{~g} / 1$ glucose monohydrate, $10 \mathrm{~g} / 1$ sodium citrate tribasic dihydrate and $2 \mathrm{~g} / 1$ sodium bicarbonate). Three replicates were evaluated for all test performed.

Osmolality and $\mathrm{pH}$ of each sample were measured using an osmometer and a $\mathrm{pH}$ probe for low volumes $(30-50 \mu \mathrm{l})$ : a cryoscopic osmometer (Osmomat-030, Gonotec $^{\mathrm{TM}}$; Berlin, Germany) and an electronic pH-meter (CG 837, Schott ${ }^{\mathrm{TM}}$; Mainz, Germany), respectively.

For motility assessment, $5 \mu \mathrm{l}$ of sample was diluted in $500 \mu \mathrm{l}$ of PBS (325 mOsm/ $\mathrm{kg}, \mathrm{pH} 7.4$ ). A $5 \mu$ drop was put on a prewarmed slide and covered with a coverslip. The sample was examined with a phase contrast microscope (Nikon Labophot-2; negative contrast optics), with a warming stage at $37^{\circ} \mathrm{C}$. At least five fields were observed at $\times 200$. A CASA system coupled was used to objectively assess motility (Motility Ana-

3 lyzer v. 7.4G, Hamilton-Thorne Research ${ }^{\mathrm{TM}}$ ), collecting the following parameters: total motility (TM; \%), progressive motility (PM; \%), average path velocity $(\mu \mathrm{m} / \mathrm{s}$; VAP), curvilinear path velocity $(\mu \mathrm{m} / \mathrm{s} ; \mathrm{VCL})$, straight path velocity $(\mu \mathrm{m} / \mathrm{s} ; \mathrm{VSL})$, linearity $(\% ; \mathrm{LIN})$, straightness $(\%$; STR), amplitude of lateral head displacement ( $\mu \mathrm{m} ; \mathrm{ALH})$ and beat cross frecuency $(\mathrm{Hz} ; \mathrm{BCF})$. A spermatozoon was considered motile when VCL $>10 \mu \mathrm{m} / \mathrm{s}$, and progressive if STR $>80 \%$. We used an image acquisition rate of 25 frames/s and an acquisition time of $0.8 \mathrm{~s}$.

The functional integrity of the sperm plasma membrane was evaluated using the hypoosmotic swelling test (HOS test). Five $\mu \mathrm{l}$ of sample was diluted in $500 \mu \mathrm{l}$ of a hypoosmotic sodium citrate solution $(100 \mathrm{mOsm} / \mathrm{kg})$. After $18 \mathrm{~min}$ at room temperature, samples were fixed with a drop of glutaraldehyde solution (5 in $500 \mu \mathrm{l} ; 2 \%$ glutaraldehyde in an aqueous solution of $146 \mathrm{~mm}$
Table 1. Composition of the three extenders used in the cryopreservation experiment and respective final osmolality

\begin{tabular}{lccc}
\hline Component & Extender 1 & Extender 2 & Extender 3 \\
\hline Tes (mm) & 211.9 & 211.9 & 194.4 \\
Tris (mm) & 76.6 & 76.6 & 64.5 \\
Fructose (mm) & 15.8 & 112.9 & 16.9 \\
Penicillin (UI/l) & $5 \times 10^{5}$ & $5 \times 10^{5}$ & $5 \times 10^{5}$ \\
Streptomycin (mg/l) & 625 & 625 & 625 \\
Egg yolk (\%, v/v) & 10 & 15 & 20 \\
Equex (\%, v/v) & & & 0.5 \\
EDTA (mg/l) & 4 & 4 & 960 \\
Glycerol (\%, v/v) & 325 & 430 & 400 \\
Osmolality & & & 300 \\
\hline
\end{tabular}

glucose, $34 \mathrm{~mm}$ sodium citrate tribasic dihydrate and $24 \mathrm{~mm}$ sodium bicarbonate). Responsiveness to the test was determined counting a minimum of 100 cells with a phase contrast microscope $(\times 400)$. Hypoosmotic swelling test reactivity was defined as $\%$ of cells with a swollen tail.

\section{Sample dilution}

The sperm sample was divided into three parts, each was diluted $1: 1$ with different extenders. The extenders were based on a Tes-Tris-buffered solution diluted in milli-Q water (Table 1), using fructose for adjusting osmolality. The solution $(\mathrm{pH} 7.2)$ was passed through a $0.2-\mu \mathrm{m}$ filter and supplemented with egg yolk and glycerol $(4 \%)$ as cryoprotectants (Kaabi et al. 2003). The choice of these three extenders was determined by the urgency of the situation and the impossibility of preparing other extenders quickly. Extender 1 was prepared for ovine semen, extender two for red deer epididymal semen and extender three for equine semen. Extended samples were transferred to a chamber set at $5^{\circ} \mathrm{C}$. After $60 \mathrm{~min}$, samples cooled at $5^{\circ} \mathrm{C}$ were diluted with the same extenders to yield the final sperm concentration of $80 \times 10^{6} \mathrm{sperm} / \mathrm{ml}$.

\section{Sample freezing}

The extended samples were packaged in $0.25-\mathrm{ml}$ straws $\left(20 \times 10^{6}\right.$ spermatozoa/straw $)$. Freezing was performed using a biofreezer (Planer Kryo-Series III ${ }^{\mathrm{TM}}$, Telstar), 4 programmed for a freezing rate of $-20^{\circ} \mathrm{C} / \mathrm{min}$, from 5 to $-100^{\circ} \mathrm{C}$. Once frozen, straws were stored in liquid nitrogen. These samples were stored in liquid nitrogen for 8 years until Natural Park Administration (Principado de Asturias Government, Spain), where the brown bear was taken, has allowed their analysis to improve our knowledge about bear reproduction technology.

\section{Assessment of thawed samples}

Samples were thawed by dropping the straws in a water bath at $65^{\circ} \mathrm{C}$ for $6 \mathrm{~s}$. After $10 \mathrm{~min}$ at room temperature, samples were analysed for motility (CASA system), agglutination [assessed visually on a microscope slide from 0 (no agglutination) to 4 (all cells agglutinated)], abnormal forms (were evaluated counting at least 100 cells per sample on a microscope slide with a phase 
contrast microscope at $\times 400$ ), and also by other method based in fluorescent probes: viability, acrosomal status and mitochondrial status. Three replicates were evaluated for all test performed, and means and standard deviations were obtained.

For viability and acrosomal status assessment, spermatozoa were stained with propidium iodide (PI; $37 \mathrm{~nm}$ in spermatozoa sample) and PNA (peanut agglutinin) conjugated with FITC $(1 \mu \mathrm{g} / \mathrm{ml}$ in spermatozoa sample). After $10 \mathrm{~min}$ at room temperature, samples were analysed. PI stains non-viable spermatozoa red, and FITC-PNA stains damaged acrosomes green. We obtained four different subpopulations: red (non-viable sperm; intact acrosome), green (viable sperm, damaged acrosome), red and green (non-viable sperm, damaged acrosome) or non-stained (viable sperm, intact acrosome).

For mitochondrial status, we used the JC-1 probe (Molecular Probes, The Netherlands; $1.4 \mu \mathrm{M}$ in spermatozoa sample), which exhibits red-orange fluorescence in mitochondria with high membrane potential, while emits green fluorescence if they are low membrane potential. After adding the probe, samples were incubated $30 \mathrm{~min}$ at $37^{\circ} \mathrm{C}$ and analysed.

For analyses with fluorescent probes, samples were previously adjusted in all cases to $1-2 \times 10^{6}$ spermato$\mathrm{zoa} / \mathrm{ml}$ in Hepes medium (20 mм Hepes, $197 \mathrm{~mm} \mathrm{NaCl}$, $2.5 \mathrm{~mm} \mathrm{KOH,} 10 \mathrm{~mm}$ glucose; pH 7, $400 \mathrm{mOsm} / \mathrm{kg}$ ), and the fluorescence was analysed using a FACScalibur flow cytometer (Becton Dickinson, Franklin Lakes, NJ). The flow cytometer was equipped with a $15-\mathrm{mW}$ argonlaser $(488 \mathrm{~nm})$. For detecting green fluorescence, we used the FL1 photodetector (530/30), the FL2 photodetector $(585 / 42)$ for orange fluorescence and the FL3 photodetector (650) for red fluorescence. At least 10000 events were acquired.

\section{Caffeine stimulation}

An aliquot of each thawed sample was diluted in PBS medium containing $5 \mathrm{~mm}$ of caffeine. The motility of the samples was analysed after $15 \mathrm{~min}$ at $37^{\circ} \mathrm{C}$.

\section{Motility recovery rates}

Motility recovery rates were calculated using the following equation: (Motility after treatment/Motility before treatment $) \times 100$. We used these rates to evaluate, for each extender, both the motility decrease because of the cryopreservation protocol (post-thawing vs fresh) and the effect of the stimulating protocol on motility (stimulated vs fresh and stimulated vs post-thawing).

\section{Results}

\section{Testicles and epididymal sample characteristics}

The testicles weighed $56.06 \mathrm{~g}$, and the epididymis weighed $14.91 \mathrm{~g}$. The isolated cauda epididymes weighed $5.90 \mathrm{~g}$ and yielded $0.21 \mathrm{~g}$ of sperm sample contained $929 \times 10^{6}$ spermatozoa $\left(4426 \times 10^{6} \mathrm{spermatozoa} / \mathrm{ml}\right)$. This sample had a $\mathrm{pH}$ of 6.75 and an osmolality of $375 \mathrm{mOsm} / \mathrm{kg}$.

\section{Quality of the fresh samples}

The sample obtained from the cauda epididymis yielded $54 \%$ motile spermatozoa, $28 \%$ of which were progressive and approximately $10 \%$ had a circular motion (Table 2). We observed some degree of head-to-head agglutination in cauda epididymis spermatozoa.

\section{Quality of thawed samples}

Motility decreased after cryopreservation (Table 2). Extender 3 showed a higher total motility than extender 2. In all cases, motility recovery rates (regarding to the fresh sample) were high for LIN parameters (LIN and STR; above $85 \%$ ) and more moderate for ALH (approximately 70\%). Notably, the motility recovery rates of $\mathrm{BCF}$ were well above $150 \%$. Nevertheless, this increase in beat cross frequency, an indirect observation of flagellar activity, did not reflected in an improvement of velocity (VAP, VCL and VSL; only approximately $50 \%$ recovery). Head-to-head agglutination was observed (Table 3). Spermatozoa cryopreserved in extenders 1 and 3 showed a slight agglutination, whereas it was more pronounced in extender 2 .

Figure 1 shows that motility recovery rates after caffeine stimulation varied greatly depending on the extender. In general, caffeine treatment had a negative effect on the motility of the spermatozoa cryopreserved with extender 1, and it barely affected spermatozoa cryopreserved with extender 3 . However, it effectively stimulated motility on extender 2 (total motility: $44.7 \%$; progressive motility: $13.3 \%$; VAP: $50.7 \mu \mathrm{m} / \mathrm{s}$ ). The
Table 2. Motility data (means \pm SD) of the fresh and thawed semen obtained from the cauda epididymis. Motility recovery rates ${ }^{\mathrm{a}}(\%)$ of the thawed samples are indicated within parentheses

\begin{tabular}{|c|c|c|c|c|}
\hline \multirow[b]{2}{*}{ Parameter } & \multirow[b]{2}{*}{ Fresh } & \multicolumn{3}{|c|}{ Thawed } \\
\hline & & Extender 1 & Extender 2 & Extender 3 \\
\hline TM $(\%)$ & 54 & $24.0 \pm 4.0(44.4)$ & $23.7 \pm 2.3(37.0)$ & $30.7 \pm 5.7(57.4)$ \\
\hline PM (\%) & 28 & $7.0 \pm 4.6(25.0)$ & $7.3 \pm 4.2(17.9)$ & $9.3 \pm 1.5(32.1)$ \\
\hline $\operatorname{VAP}(\mu \mathrm{m} / \mathrm{s})$ & 86 & $43.0 \pm 12.2(50.0)$ & $38.0 \pm 13.5(44.2)$ & $54.0 \pm 6.6(62.8)$ \\
\hline VCL $(\mu \mathrm{m} / \mathrm{s})$ & 131 & $66.3 \pm 18.6(50.4)$ & $63.3 \pm 19.8(48.1)$ & $74.0 \pm 8.9(56.5)$ \\
\hline $\operatorname{VSL}(\mu \mathrm{m} / \mathrm{s})$ & 68 & $31.0 \pm 14.0(45.6)$ & $27.3 \pm 11.9(39.7)$ & $39.3 \pm 4.5(57.4)$ \\
\hline LIN $(\%)$ & 55 & $52.0 \pm 6.1(94.5)$ & $46.3 \pm 9.0(83.6)$ & $53.3 \pm 5.9(96.4)$ \\
\hline STR $(\%)$ & 79 & $71.0 \pm 6.1(89.9)$ & $69.0 \pm 8.9(87.3)$ & $72.0 \pm 1.7(91.1)$ \\
\hline $\mathrm{ALH}(\mu \mathrm{m})$ & 6.3 & $4.3 \pm 2.3(68.3)$ & $4.9 \pm 1.4(77.8)$ & $4.6 \pm 1.5(73.0)$ \\
\hline $\mathrm{BCF}(\mathrm{Hz})$ & 5.6 & $10.0 \pm 2.6(178.6)$ & $12.4 \pm 2.8(221.4)$ & $9.5 \pm 2.9(169.6)$ \\
\hline
\end{tabular}

${ }^{a}$ Motility after thawing/Motility before freezing (Fresh) $\times 100$.

ALH, amplitude of lateral head; BCF, beat cross frecuency; LIN, linearity; PM, progressive motility; STR, straightness; VAP, average path velocity; VCL, curvilinear path velocity; VSL, straight path velocity. 
Table 3. Percentage of sperm from the cauda epididymis with abnormal morphology after freezing-thawing in different extenders

\begin{tabular}{lrcr}
\hline & \multicolumn{3}{c}{ Thawed (Cauda) } \\
\cline { 2 - 4 } & \multicolumn{3}{c}{ Extender } \\
\cline { 2 - 4 } Parameter & 1 & 2 & 3 \\
\hline Abnormality & 8 & 10 & 6 \\
$\quad$ Head & 3 & 6 & 1 \\
Midpiece & 3 & 1 & 13 \\
Tail & 14 & 17 & 1 \\
Total & 2 & 3 & \\
Agglutination & & & \\
\hline
\end{tabular}

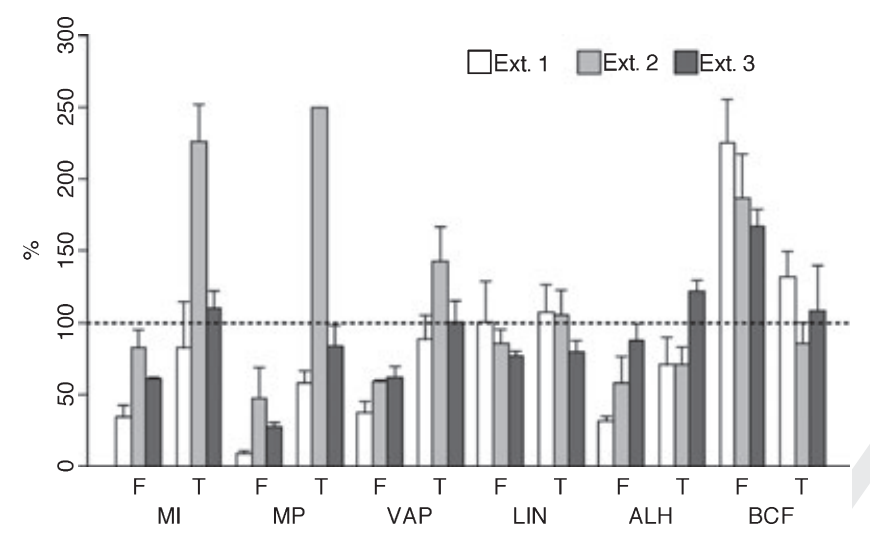

Fig. 1. Motility recovery after caffeine stimulation of thawed samples from the cauda epididymis, calculated for the three extenders assayed (ext. 1, ext. 2 and ext. 3). $\mathrm{F}$ is the recovery rate from the fresh sample (value after stimulation/value of the fresh sample $\times 100$ ), and $\mathrm{T}$ is the recovery rate from the thawed sample (value after stimulation/value of the thawed sample $\times 100)$. Results are means and standard deviations of triplicates (For details of motility parameters see Materials and Methods)

motility of stimulated spermatozoa is higher than that of non-stimulated, both in fresh and in post-thawing samples (Fig. 1). Moreover, the recovery rate obtained for stimulated/fresh was higher than for post-thawed/ fresh (Table 2).

The HOS test showed $25 \%, 34 \%$ and $33 \%$ reactive sperm (functional membranes) for extenders 1, 2 and 3, respectively. As for abnormal forms, the three extenders show similar values $(13-17 \%)$ principally located in head (Table 3).

Extender 2 showed the higher results for viability, acrosome integrity and mitochondrial status: $66.9 \%$ viable with intact acrosome and $67.1 \%$ with high mitochondrial activity (Table 4). Overall, the other

Table 4. Percentages (means \pm SD) of sperm according to acrosomal status and mitochondrial membrane potential evaluated by flow cytometry on frozen-thawed samples from the cauda epididymis

\begin{tabular}{lccrc}
\hline Parameter & Staining & Extender 1 & Extender 2 & Extender 3 \\
\hline $\begin{array}{l}\text { Acrosome-intact/ } \\
\text { non-viable }\end{array}$ & PI + /PNA- & $54.8 \pm 4.7$ & $27.7 \pm 4.8$ & $50.3 \pm 1.1$ \\
$\begin{array}{l}\text { Acrosome-intact/ } \\
\text { viable }\end{array}$ & PI-/PNA- & $31.7 \pm 6.1$ & $64.0 \pm 8.1$ & $34.1 \pm 1.6$ \\
$\begin{array}{l}\text { Acrosome-damaged } \\
\text { Active mitochondria }\end{array}$ & PI + JC-1 red & $48.8 \pm 15.8$ & $67.1 \pm 4.1$ & $47.7 \pm 2.8$ \\
\hline
\end{tabular}

two extenders showed only approximately $33 \%$ viable spermatozoa with intact acrosome and approximately $47 \%$ spermatozoa with active mitochondria.

\section{Discussion}

In this study, we have shown the application of emergency procedures for the cryopreservation of epididymal spermatozoa from one Cantabrian brown bear. Although we processed only one male, we think that the information is valuable, both from descriptive and applicative perspectives. There are no previous studies on epididymal spermatozoa from brown bear, and obtaining such samples, especially from the endangered Cantabrian brown bear, is a very rare event.

We have to take into account that we obtained the sperm sample by slicing the epididymis. Although in this experiment we chose to extract the spermatozoa by cuts because of the urgency and to recover most samples, there are other methods for obtaining the sperm sample post-mortem, which may result in improved quality. In a previous study (Martinez-Pastor et al. 2006a,b), we $\mathbf{5}$ found that sperm samples obtained from the cauda epididymis canulating the vas deferens and flushing had less blood and somatic cell contamination that when using cuts. Moreover, quality and freezability seemed to improve. Nevertheless, the differences were not dramatic, and possibly, cuts are an acceptable method in emergency procedures.

The breeding season of the Cantabrian brown bear comprises, approximately, May and June (Fernández-Gil et al. 2006), and the sample described in this study was $\mathbf{6}$ obtained in April, just before the mating season. It is possible that some of the characteristics found in the fresh sample were because of this fact. Thus, the percentages of abnormal spermatozoa we found in the cauda epididymis (20\%, Anel et al. 1999) could be normal. Our results are comparable to others in which sperm samples were obtained during the breeding season using electroejaculation $(21.8 \%$, Ishikawa et al. 1998; 21.5\%, Ishikawa et al. 2002b). In fact, spermatogenesis was possibly active by the collection date, as suggested by other studies in bears (Tsubota and Kanagawa 1989). Nevertheless, considering the quantity of spermatozoa obtained (almost $10^{9}$ spermatozoa), we cannot neglect samples harvested before the breeding season, because an important number of sperm doses might be obtained from them.

However, other parameters differ importantly between ejaculated and post-mortem samples. In a previous study with electroejaculated semen from brown bear (Anel et al. 2002b), we obtained an average $\mathrm{pH}$ and osmolality of 8.65 and $328 \mathrm{mOsm} / \mathrm{kg}$, respectively, whereas in this study these parameters were 6.75 and $375 \mathrm{mOsm} / \mathrm{kg}$. Lower $\mathrm{pH}$ and higher osmolality are physiological traits of the epididymal environment (De Pauw et al. 2003), and this must be taken into account when managing this kind of samples. Sperm motility shows a lower value than the motility reported on fresh or cryopreserved ejaculates (Ishikawa et al. 1998, 2002b; Anel et al. 2003). It is known that the epididymal environment inhibits the motility of spermatozoa, and they may require an appropriate treatment to acquire their full motility. Moreover, we cannot discard an effect 
of season, because the samples used in these studies were collected during the breeding season. Nevertheless, postthawing recovery rates for motility obtained in our study were in the same range that those of ejaculated semen (Ishikawa et al. 2002b).

Extender 2 was possibly the most appropriate option for freezing the sample. Although it did not excel considering motility, fluorescent techniques indicated more viable spermatozoa, less damaged acrosomes and more mitochondria-active spermatozoa after thawing when using this extender. Furthermore, after caffeine stimulation, the spermatozoa cryopreserved using extender 2 showed a higher motility above thawing, whereas the other two extenders failed in showing such a response. The extender used by Ishikawa et al. (2002b) had the same concentration of egg yolk (15\%) and glycerol $(4.7 \%)$ than extender 2 , obtaining similar motility and viability results. We have to consider that the sample source (electoejaculated vs epididymal) and season (breeding season vs prebreeding season) were different, and, in fact, the base diluent of extender 2 (before adding cryoprotectants) had an osmolality of $430 \mathrm{mOsm} / \mathrm{kg}$, more adequate for epididymal samples. Previous studies in ruminants have showed that epididymal fluid has a much higher osmolality than seminal plasma and that adjusting the osmolality of the extender accordingly might improve cryopreservation results (Martinez-Pastor et al. 2006a,b; Fernández-Santos et al. 2007; Martínez et al. 2008). In fact, the effectiveness of this extender suggests that their composition is adequate for bear sperm and that they may be a starting point for developing optimized extenders for this species. A possible handicap for extender 2 would be sperm agglutination, which was especially high after thawing. Other authors have reported a generalized incidence of sperm agglutination on bear sperm (Kojima et al. 2001). The incidence was minimal in extender 3, maybe because of the presence of EDTA and Equex as additives. Thus, the formulation of extender 2 must be improved to prevent high agglutination rates. Moreover, agglutination might have a role in the low post-thawing motility of spermatozoa.

In conclusion, post-mortem sperm recovery in brown bear can be performed easily, obtaining a considerable amount of spermatozoa, even in the pre-breeding period. The cryopreservation of this kind of samples is feasible, and extender composition is one important factor for a good outcome of the technique. The development of a standardized method for this kind of samples should greatly help brown bear conservation, especially of endangered breeds, such as Cantabric brown bear populations. Although epididymal sperm may present mediocre characteristics (motility), it may be successfully utilized on IVF or ICSI procedures, if not in AI However, further opportunities to study this kind of samples should be useful to assess samples collected at different times of the year and to evaluate their actual fertility potential.

\section{Acknowledgements}

The authors thank to the rangers of the Patrulla Oso and to Servicio de Medio Natural of Consejería de Medio Ambiente del Principado de Asturias (Spain); and V. García, M. Kaabi, A. R. Díaz, J. D. Muro,
A. Sánchez and M. González for their help in the analysis of the samples. This work was supported in part by CICYT (CGL 200402178/BOS and CGL 2007-63748/BOS). Felipe Martínez-Pastor was supported by the Juan de la Cierva and the Ramon y Cajal programs (Spanish Ministry of Education and Science).

\section{Conflict of Interest}

$\operatorname{xxx} \operatorname{xxxxxxxxxx}$

\section{Author contributions}

L Anel has designed the research, acquisition and analysis of data, and to drafting the paper. M Álvarez also designed the research, acquisition and analysis of data. E Anel, F Martínez-Pastor, F Martínez, C Chamorro carried out the acquisition and analysis of data. $\mathrm{P}$ de Paz has designed the research, the acquisition and analysis of data, and to drafting the paper.

\section{References}

Anel L, Martinez F, Alvarez M, Anel E, Boixo J, Kaabi M, Paz P, Chamorro C, Herraez P, 1999: Post-mortem spermatozoa recovery and freezing in a Cantabric brown bear (Ursus arctos): a preliminary report. Theriogenology 51, 277.

Anel L, Guerra C, Alvarez M, Anel E, Martinez A, Boixo J, Kaabi M, Herraez P, Paz P, 2002a: Effect of post-mortem interval on quality of epididymal spermatozoa in Iberian red deer (Cervus elaphus hispanicus). Theriogenology 57, 577.

Anel L, Martinez-Pastor F, Anel E, Alvarez M, Martinez F, Borragan S, Celada M, Boixo J, Herraez P, Paz P 2002b. Evaluation of urospermia in European brown bear (Ursus arctos) electroejaculation. In: The Second International Symposium on Assisted Reproductive Technology (ART) for the Conservation and Genetic Management of Wildlife. Omaha, Nebraska, USA

Anel L, Anel E, Alvarez M, Garcia-Macias V, Martinez F, Borragan S, Celada M, Herraez P, Paz P, 2003: Computerized analysis of sperm motility in European brown bear (Ursus arctos) semen. Theriogenology 59, 386.

Anel L, Alvarez M, Martínez-Pastor F, Gomes S, Nicolás M, Mata M, Martínez AF, Borragán S, Anel E, de Paz P, 2008: Sperm cryopreservation in brown bear (Ursus arctos): preliminary aspects. Reprod Domest Anim 43, 9-17.

Boone WR, Keck BB, Catlin JC, Casey KJ, Boone ET, Dye PS, Schuett RJ, Tsubota T, Bahr JC, 2004: Evidence that bears are induced ovulators. Theriogenology 61, 11631169.

Chapron G, Quenette PY, Legendre S, Clobert J, 2003: Which future for the French Pyrenean brown bear (Ursus arctos) population? An approach using stage-structured deterministic and stochastic models. C R Biol 326(Suppl. 1), 174-182.

Clevenger AP, Purroy FJ, Campos MA, 1997: Habitat assessment of a relict brown bear Ursus arctos population in northern Spain. Biol Conserv 80, 17-22.

De Pauw IM, Van Soom A, Mintiens K, Verberckmoes S, de Kruif A, 2003: In vitro survival of bovine spermatozoa stored at room temperature under epididymal conditions. Theriogenology 59, 1093-1107.

Fernández-Gil A, Naves J, Delibes M, 2006: Courtship of brown bears Ursus arctos in northern Spain: phenology, weather, habitat and durable mating areas. Wildl Biol 12, 367-373.

Fernández-Santos MR, Martínez-Pastor F, García-Macías V, Esteso MC, Soler AJ, de Paz P, Anel L, Garde JJ, 2007: Extender osmolality and sugar supplementation exert a complex effect on the cryopreservation of Iberian red deer 
(Cervus elaphus hispanicus) epididymal spermatozoa. Theriogenology 67, 738-753.

Fickel J, Wagener A, Ludwig A, 2007: Semen cryopreservation and the conservation of endangered species. Eur J Wildl Res 53, 81-89.

Garcia-Macias V, Martinez-Pastor F, Alvarez M, Borragan S, Celada M, Chamorro C, Herraez P, Paz P, Anel L 2004 Viability and acrosomal status in brown bear (Ursus arctos) sperm before and after cryopreservation. In: 15th International Congress on Animal Reproduction. Porto Seguro, Brazil, 2, p. 529.

García-Macías V, Martínez-Pastor F, Álvarez M, Borragán S, Anel L, de Paz P, 2006: Seasonal changes in sperm chromatin condensation in ram (Ovis aries), red deer (Cervus elaphus)

9 and brown bear (Ursus arctos). J Androl 27, 837-846.

Holt WV, Watson PF, 2001: Gamete cryopresevation and reproductive technologies in miscellaneous mammals. In: Watson PF, Holt WV (eds), Cryobanking the Genetic Resource: Wildlife Conservation for the Future? Taylor and Francis, London, pp. 391-406.

Hori T, Ichikawa M, Kawakami E, Tsutsui T, 2004: Artificial insemination of frozen epididymal sperm in beagle dogs. J Vet Med Sci 66, 37-41.

Ishikawa A, Matsui M, Tsuruga H, Sakamoto H, Takahashi Y, Kanagawa H, 1998: Electroejaculation and semen characteristics of the captive Hokkaido brown bear (Ursus arctos yesoensis). J Vet Med Sci 60, 965-968.

Ishikawa A, Kikuchi S, Katagiri S, Sakamoto H, Takahashi Y, 2002a: Efficiency of fecal steroid hormone measurement for assessing reproductive function in the Hokkaido brown bear (Ursus arctos yesoensis). Jpn J Vet Res 50, 17-27.

Ishikawa A, Matsui M, Sakamoto H, Katagiri S, Takahashi Y, 2002b: Cryopreservation of the semen collected by electroejaculation from the Hokkaido brown bear (Ursus arctos yesoensis). J Vet Med Sci 64, 373-376.

Kaabi M, Paz P, Alvarez M, Anel E, Boixo JC, Rouissi H, Herraez P, Anel L, 2003: Effect of epididymis handling conditions on the quality of ram spermatozoa recovered post-mortem. Theriogenology 60, 1249-1259.

Kojima E, Tsuruga H, Komatsu T, Murase T, Tsubota T, Kita I, 2001: Characterization of semen collected from beagles and captive Japanese black bears (Ursus thibetanus japonicus). Theriogenology 55, 717-731.

Komatsu T, Yamamoto Y, Atoji Y, Tsubota T, Suzuki Y, 1997: Seasonal changes in subcellular structures of Leydig and Sertoli cells in the Japanese black bear, ursus thibetanus japonicus. Arch Histol Cytol 60, 225-234.

Laikre L, Andren R, Larsson HO, Ryman N, 1996: Inbreeding depression in brown bear Ursus arctos. Biol Conserv 76, 6972.

Leibo S, Songsasen N, 2002: Cryopreservation of gametes and embryos of non-domestic species. Theriogenology 57, 303 326.

Martínez AF, Martinez-Pastor F, Álvarez M, FernándezSantos MR, Esteso MC, de Paz P, Garde JJ, Anel L, 2008:
Sperm parameters on Iberian red deer: electroejaculation and post-mortem collection. Theriogenology 70, 216-226.

Martinez-Pastor F, Guerra C, Kaabi M, Diaz AR, Anel E, Herraez P, de Paz P, Anel L, 2004: Decay of sperm obtained from epididymes of wild ruminants depending on postmortem time. Theriogenology 63, 24-40.

Martinez-Pastor F, Martínez F, García-Macías V, Esteso MC, Anel E, Fernández-Santos MR, Soler AJ, de Paz P, Garde J, Anel L, 2006a: A pilot study on post-thawing quality of Iberian red deer spermatozoa (epididymal and electroejaculated) depending on glycerol concentration and extender osmolality. Theriogenology 66, 1165-1172.

Martinez-Pastor F, Garcia-Macias V, Alvarez M, Chamorro C, Herraez P, de Paz P, Anel L, 2006b: Comparison of two methods for obtaining spermatozoa from the cauda epididymis of Iberian red deer. Theriogenology 65, 471-485.

Mortimer D, Serres C, Mortimer ST, Jouannet P, 1988: Influence of image sampling frequency on the perceived movement characteristics of progressively motile human spermatozoa. Gamete Res 20, 313-327.

Sato M, Ishikawa A, 2004: Room temperature storage of mouse epididymal spermatozoa: exploration of factors affecting sperm survival. Theriogenology 61, 1455-1469.

Sato M, Tsubota T, Komatsu T, Watanabe G, Taya K, Murase T, Kita I, Kudo T, 2001: Changes in sex steroids, gonadotropins, prolactin, and inhibin in pregnant and nonpregnant japanese black bears (Ursus thibetanus japonicus). Biol Reprod 65, 1006-1013.

Soler AJ, Perez-Guzman MD, Garde JJ, 2003: Storage of red deer epididymides for four days at 5 degrees C: effects on sperm motility, viability, and morphological integrity. J Exp Zoolog Part A Comp Exp Biol 295, 188-199.

Taberlet P, Bouvet J, 1994: Mitochondrial DNA polymorphism, phylogeography, and conservation genetics of the brown bear Ursus arctos in Europe. Proc R Soc Lond B Biol Sci 255, 195-200.

Tsubota T, Kanagawa H, 1989: Annual changes in serum testosterone levels and spermatogenesis in the Hokkaido brown bear (Ursus arctos yesoensis). J Mammal Soc Jpn 14, $11-17$.

Tsubota T, Howell-Skalla L, Nitta H, Osawa Y, Mason JI, Meiers PG, Nelson RA, Bahr JM, 1997: Seasonal changes in spermatogenesis and testicular steroidogenesis in the male black bear Ursus americanus. J Reprod Fertil 109, 21-27.

Tsutsui T, Wada M, Anzai M, Hori T, 2003: Artificial insemination with frozen epididymal sperm in cats. J Vet Med Sci 65, 397-399.

Submitted: 12 Dec 2009; Accepted: 16 Apr 2010

Author's address (for correspondence): Luis Anel Rodríguez, Animal Reproduction and Obstetrics, University of León, León 24071, Spain. E-mail: laner@unileon.es 


\section{Author Query Form}

Journal: $\quad$ RDA

Article: $\quad 1646$

Dear Author,

During the copy-editing of your paper, the following queries arose. Please respond to these by marking up your proofs with the necessary changes/additions. Please write your answers on the query sheet if there is insufficient space on the page proofs. Please write clearly and follow the conventions shown on the attached corrections sheet. If returning the proof by fax do not write too close to the paper's edge. Please remember that illegible mark-ups may delay publication.

Many thanks for your assistance.

\begin{tabular}{|c|c|c|}
\hline $\begin{array}{l}\text { Query } \\
\text { reference }\end{array}$ & Query & Remarks \\
\hline Q1 & $\begin{array}{l}\text { AUTHOR: Komatsu at al. } 1997 \text { has been changed to Komatsu et al. } 1997 \text { so } \\
\text { that this citation matches the Reference List. Please confirm that this is } \\
\text { correct. }\end{array}$ & \\
\hline Q2 & AUTHOR: Please provide city name for Sigma. & \\
\hline Q3 & $\begin{array}{l}\text { AUTHOR: Please give manufacturer information for Hamilton-Thorne } \\
\text { Research }^{\mathrm{TM}} \text { : company name, town, state (if USA), and country. }\end{array}$ & \\
\hline Q4 & $\begin{array}{l}\text { AUTHOR: Please give manufacturer information for Planer Kryo-Series } \\
\text { III }^{\mathrm{TM}} \text { : company name, town, state (if USA), and country. }\end{array}$ & \\
\hline Q5 & $\begin{array}{l}\text { AUTHOR: Martinez-Pastor et al., } 2006 \text { has been changed to Martinez- } \\
\text { Pastor et al. 2006a, 2006b so that this citation matches the Reference List. } \\
\text { Please confirm that this is correct. }\end{array}$ & \\
\hline Q6 & $\begin{array}{l}\text { AUTHOR: Fernandez-Gil et al. } 2006 \text { has been changed to Fernández-Gil } \\
\text { et al. } 2006 \text { so that this citation matches the Reference List. Please confirm } \\
\text { that this is correct. }\end{array}$ & \\
\hline Q7 & $\begin{array}{l}\text { AUTHOR: Martinez et al. } 2008 \text { has been changed to Martínez et al. } 2008 \\
\text { so that this citation matches the Reference List. Please confirm that this is } \\
\text { correct. }\end{array}$ & \\
\hline Q8 & $\begin{array}{l}\text { AUTHOR: Please supply a conflict of interest statement (in accordance with } \\
\text { the Author Guidelines), along with all other proof corrections. }\end{array}$ & \\
\hline Q9 & $\begin{array}{l}\text { AUTHOR: García-Macías et al. (2006) has not been cited in the text. } \\
\text { Please indicate where it should be cited; or delete from the Reference List. }\end{array}$ & \\
\hline Q10 & $\begin{array}{l}\text { AUTHOR: Mortimer et al. (1988) has not been cited in the text. Please } \\
\text { indicate where it should be cited; or delete from the Reference List. }\end{array}$ & \\
\hline
\end{tabular}




\section{USING E-ANNOTATION TOOLS FOR ELECTRONIC PROOF CORRECTION}

\section{Required Software}

Adobe Acrobat Professional or Acrobat Reader (version 7.0 or above) is required to e-annotate PDFs. Acrobat 8 Reader is a free download: http://www.adobe.com/products/acrobat/readstep2.html

Once you have Acrobat Reader 8 on your PC and open the proof, you will see the Commenting Toolbar (if it does not appear automatically go to Tools>Commenting>Commenting Toolbar). The Commenting Toolbar looks like this:

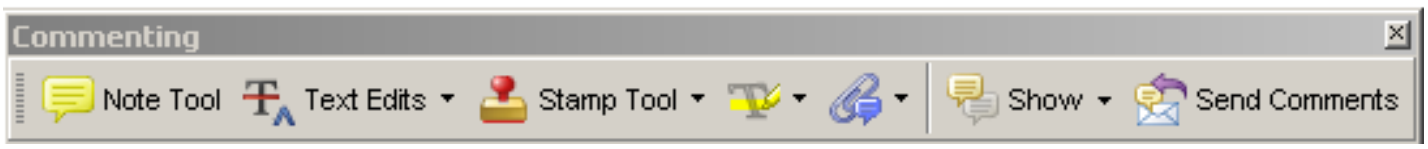

If you experience problems annotating files in Adobe Acrobat Reader 9 then you may need to change a preference setting in order to edit.

In the "Documents" category under "Edit - Preferences", please select the category 'Documents' and change the setting "PDF/A mode:" to "Never".

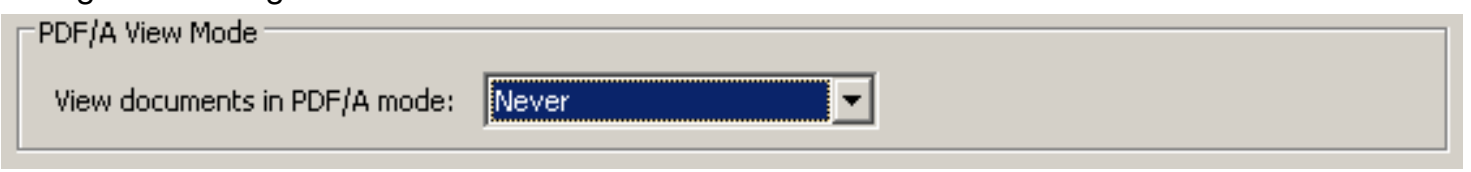

\section{Note Tool - For making notes at specific points in the text}

Marks a point on the paper where a note or question needs to be addressed.

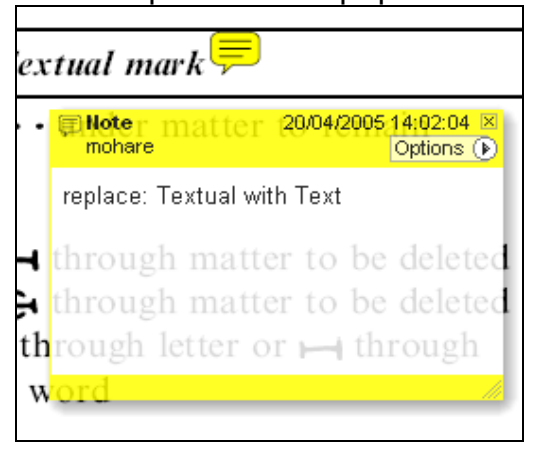

How to use it:

1. Right click into area of either inserted text or relevance to note

2. Select Add Note and a yellow speech bubble symbol and text box will appear

3. Type comment into the text box

4. Click the $X$ in the top right hand corner of the note box to close.

Replacement text tool - For deleting one word/section of text and replacing it

Strikes red line through text and opens up a replacement text box.

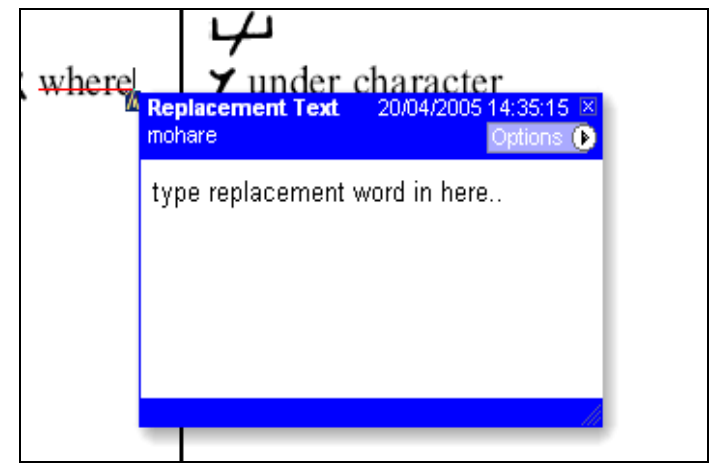

\section{How to use it:}

1. Select cursor from toolbar

2. Highlight word or sentence

3. Right click

4. Select Replace Text (Comment) option

5. Type replacement text in blue box

6. Click outside of the blue box to close

Cross out text tool - For deleting text when there is nothing to replace selection Strikes through text in a red line.

\begin{tabular}{|l|}
\hline substitute part of one or \\
more word(s) \\
Change to italies \\
Change to capitals \\
Change to small capitals \\
\hline
\end{tabular}
How to use it:
1. Select cursor from toolbar
2. Highlight word or sentence
3. Right click
4. Select Cross Out Text 


\section{(W)WILEY-BLACKWELL}

Approved tool - For approving a proof and that no corrections at all are required.

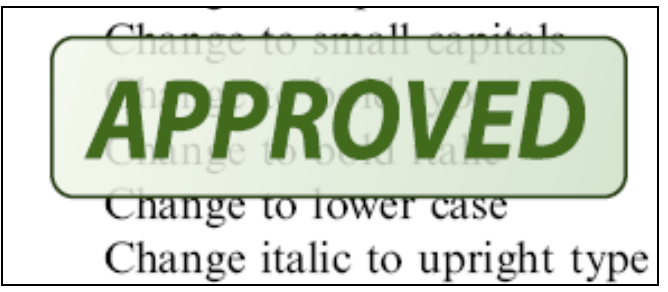

How to use it:

1. Click on the Stamp Tool in the toolbar

2. Select the Approved rubber stamp from the 'standard business' selection

3. Click on the text where you want to rubber stamp to appear (usually first page)

Highlight tool — For highlighting selection that should be changed to bold or italic. Highlights text in yellow and opens up a text box.

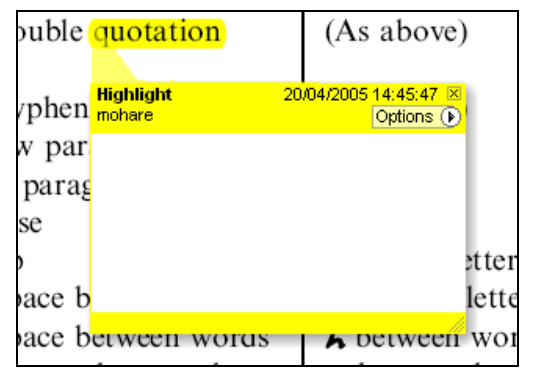

How to use it:

1. Select Highlighter Tool from the commenting toolbar

2. Highlight the desired text

3. Add a note detailing the required change

Attach File Tool - For inserting large amounts of text or replacement figures as a files. Inserts symbol and speech bubble where a file has been inserted.

\section{matter to be changed matter to matter to be changed matter to be changed} How to use it:

1. Click on paperclip icon in the commenting toolbar

2. Click where you want to insert the attachment

3. Select the saved file from your PC/network

4. Select appearance of icon (paperclip, graph, attachment or tag) and close

\section{Pencil tool - For circling parts of figures or making freeform marks}

Creates freeform shapes with a pencil tool. Particularly with graphics within the proof it may be useful to use the Drawing Markups toolbar. These tools allow you to draw circles, lines and comment on these marks.

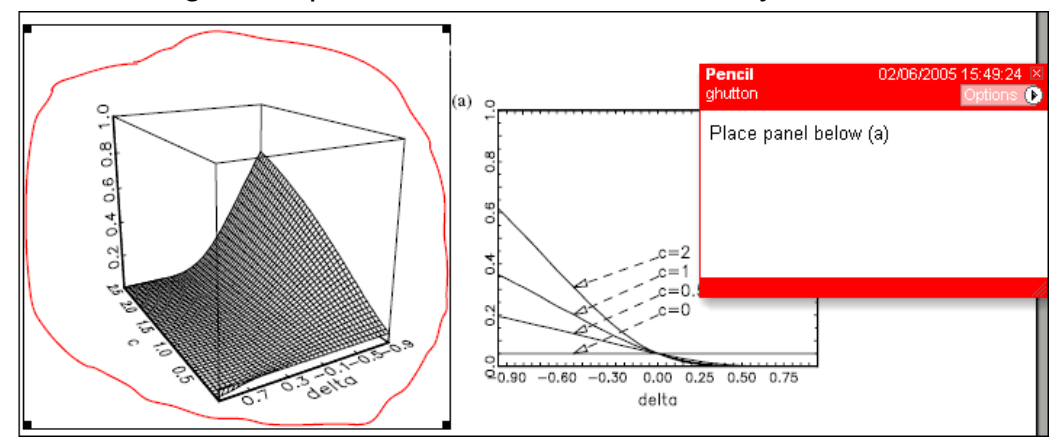

How to use it:

1. Select Tools $>$ Drawing Markups $>$ Pencil Tool

2. Draw with the cursor

3. Multiple pieces of pencil annotation can be grouped together

4. Once finished, move the cursor over the shape until an arrowhead appears and right click

5. Select Open Pop-Up Note and type in a details of required change

6. Click the $\mathrm{X}$ in the top right hand corner of the note box to close. 


\section{WILEY-BLACKWELL}

Help

For further information on how to annotate proofs click on the Help button to activate a list of instructions:

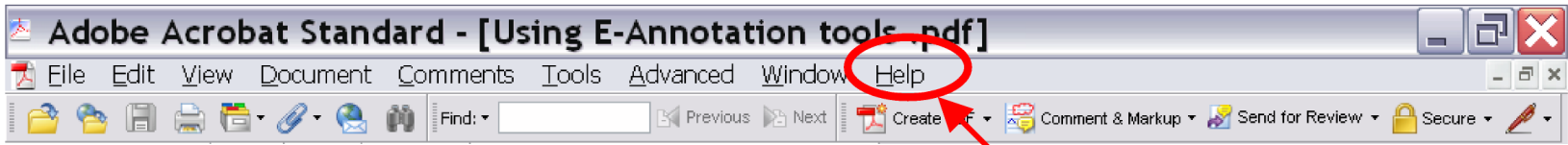

